\title{
El desacato de criticar
}

\author{
Marta Lamas
}

Una de las formas de manifestación del amor, el amor sexual, nos ha procurado la experiencia más intensa de sensación placentera avasalladora, dándonos así el arquetipo para nuestra aspiración a la dicha. Nada más natural que obstinarnos en buscar la dicha por el mismo camino siguiendo el cual una vez la hallamos.

S. FREUD

$\mathrm{M}$

I LECTURA DE ESTE conjunto de trabajos sobre sexualidad estuvo marcada por el entusiasmo a priori que tengo por un tema todavía escasamente tratado en el ámbito antropológico. ${ }^{1}$ Le agradezco a Margarita Dalton la invitación a hacer un comentario pues, además, disfruté al encontrarle cierta legitimación académica a mi añejo vicio de lectora morbosa. Pero quiero transformar la incitación que me hizo Dalton a ser "muy crítica y crear polémica" y más bien compartir con ustedes ciertas consideraciones sobre los desafíos para abordar investigaciones y reflexiones relativas a la sexualidad humana.

MARTA LAMAS: Doctora en antropología, fundadora y directora de la revista Debate Feminista, directora de Grupo de Información en Reproducción Elegida, A.C. (GIRE).

${ }^{1}$ El clásico ensayo de Carol Vance, citado en la bibliografía, sobre la antropología descubriendo a la sexualidad ofrece pistas interesantes.

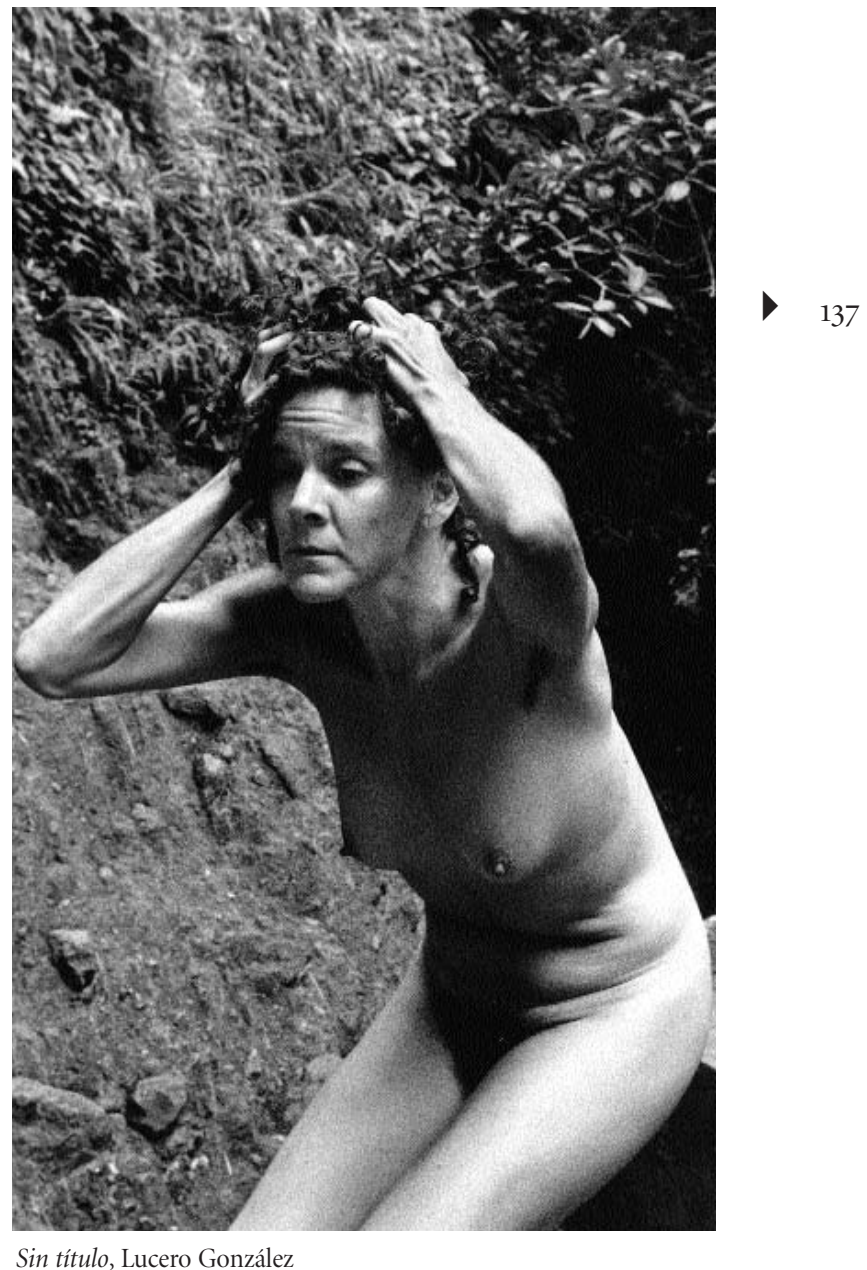




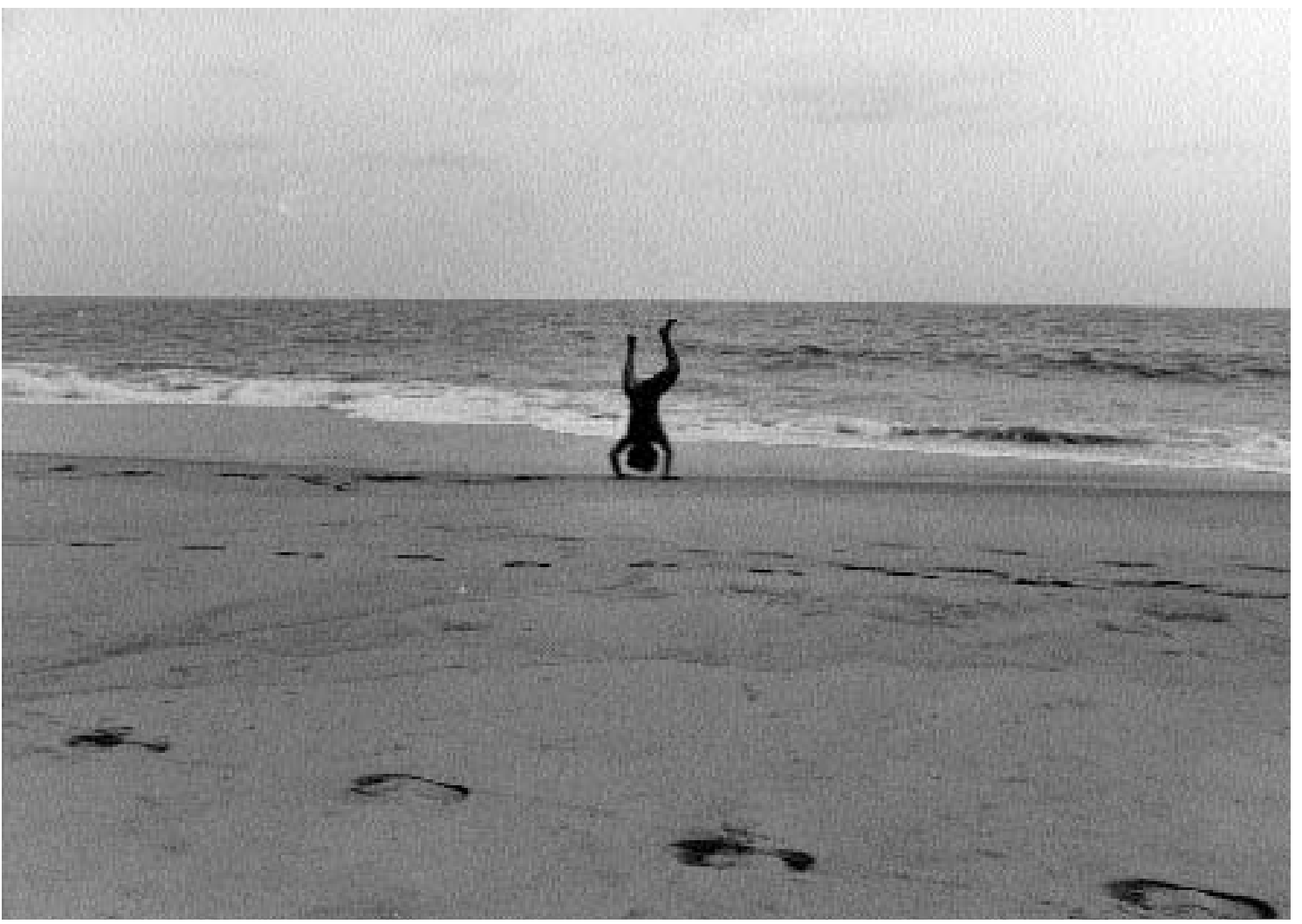

Malabar I, Jorge Acevedo

Los artículos que aquí aparecen publicados represen$\tan$ en cierto sentido la vanguardia de la investigación antropológica sobre sexualidad en nuestro país. Ante el frío desinterés que priva en nuestro medio por temas relativos a la sexualidad, un mérito indudable de les autores $^{2}$ radica en su voluntad de indagar, a pesar de lo incómodo que todavía resulta el tema. Es significativo que se publiquen en una revista con el nombre de Desacatos, y también que yo sienta que cometo un desacato, pues son investigadores que están abriendo brecha. Con el respeto que me merecen voy a hacer un comentario general, en vez de tratar a cada ensayo por separado, he preferido

\footnotetext{
${ }^{2}$ Una forma de resistir el androcentrismo del castellano es usar cada vez las y los autores. Comparto con Antonio Alatorre la esperanza de que empecemos a utilizar la "e" como referencia que incluye a ambos sexos.
}

centrarme en cuestiones de índole teórica. Probablemente la ausencia de un espacio de debate sobre la sexualidad humana hace que, no obstante el valor que tienen estos trabajos, tengan también algunas omisiones que no me es posible ignorar. Voy, por lo tanto, a señalar algunas cuestiones que me hubiera gustado que les autores trataran o profundizaran más.

El estudio de la sexualidad humana es una tarea compleja. Dos razones de tal complejidad me parecen apasionantes: porque el análisis del deseo sexual se vuelve un territorio privilegiado de la interrogación sobre el sujeto y también porque es un gran desafío intelectual intentar esclarecer los procesos psíquicos y culturales mediante los cuales las personas nos convertimos en heterosexuales y homosexuales, en bisexuales, transexuales y transgéneros, dentro de un esquema que postula la complementariedad de los sexos y la normatividad de la heterosexualidad. 
Por ello la sexualidad es más que un proceso que articula cuerpos y prácticas: expresa imaginarios y los vincula con lo simbólico. Los encuentros eróticos de cuerpos sexuados y con inconsciente recrean formas diversas de recepción del mandato de la cultura en la psique individual: aceptación, resistencia, transgresión. La manera en que el sujeto como un ser sexuado y hablante asume, inconsciente e imaginariamente, su sexuación, es especialmente relevante en la formación de su orientación sexual. $^{3}$

En el ámbito de los estudiosos de la sexualidad humana un tema central es: qué determina la orientación sexual. Básicamente ${ }^{4}$ hay dos cuerpos, por lo tanto la gran interrogante es, al margen de las valoraciones culturales que se puedan dar, ¿por qué unas personas se erotizan con cuerpos iguales a los suyos, y otras con cuerpos diferentes? Desde hace unos veinte años se ha perfilado un debate entre dos posiciones encontradas: la de quienes consideran que la orientación sexual está determinada y de quienes sostienen que la orientación sexual de una persona no es intrínseca, sino que es relacional y está marcada social e históricamente. A esta contraposición, que reproduce otra oposición clásica en antropología (la de naturaleza versus cultura), se le han puesto las etiquetas de "esencialistas" y "constructivistas". El debate a su vez se ha desdoblado en posturas entre los voluntaristas y los deterministas, que plantean cuestiones antagónicas en torno a la posibilidad de transformar a voluntad la orientación sexual o que las personas decidan en qué categoría sexual se encuentran. ${ }^{5}$

\footnotetext{
${ }^{3}$ Hay un debate, en el que no puedo entrar aquí, sobre si se debe hablar de "orientación" sexual o de "identidad" sexual. En este ensayo los uso de manera indistinta.

${ }^{4}$ Existen los intersexos, pero en términos simbólico e imaginarios, en nuestra cultura se reconocen sólo dos sexos. Véase Anne Fausto Sterling, "The Five Sexes. Why Male and Female are Not Enough", en The Sciences, marzo / abril, 1993.

${ }^{5}$ Curiosamente, no todos los esencialistas son deterministas ni todos los constructivistas sociales son voluntaristas. Una cuidadosa revisión de las posibles combinaciones entre esas cuatro categorías (esencialistas, constructivistas, voluntaristas y deterministas) la hace Edward Stein en "The Essentials of Constructionism and the Construction of Essentialism", en la antología que él compila: Forms of Desire. Sexual Orientation and the Social Constructionist Controversy, Routledge, Londres, 1992.
}

Ahora bien, una conceptualización más completa y compleja sobre los seres humanos conduce a incursionar en cuestiones fundamentales como la existencia de una realidad psíquica y a reconocer la estructuración inconsciente del deseo como un aspecto en la formación de la orientación sexual del sujeto. La teoría psicoanalítica ofrece el recuento más complejo y detallado, hasta el momento, de la constitución de la subjetividad y de la sexualidad, así como del proceso mediante el cual el sujeto resiste o se somete al código cultural. El amplio y complejo panorama de fantasías, deseos e identificaciones detectado por el psicoanálisis describe la necesidad humana de tener una identidad sexual y también muestra que las formas que esa identidad toma jamás son fijas. Pero si bien la perspectiva psicoanalítica sirve para descifrar el intrincado proceso de resistencia y asimilación del sujeto ante fuerzas culturales y psíquicas, también alude a cuestiones estructurales y transhistóricas o transculturales. Esta "doble" vertiente del psicoanálisis complica su ubicación en cualquiera de los dos lados del debate entre "esencialistas" y "constructivistas". Hay quienes consideran que el psicoanálisis es esencialista, mientras que muchísimos constructivistas citan a Freud para avalar sus planteamientos.

La tendencia del constructivismo social la impulsaron fundamentalmente autores ingleses que, por razones lingüísticas y geográficas, estaban situados de manera privilegiada entre la cultura estadounidense y la francesa. De ahí que, por un lado, tomaran elementos de la teoría norteamericana del "etiquetamiento" (labeling theory), ${ }^{6} \mathrm{cu}-$ ya idea central es que la respuesta social ante las llamadas desviaciones afecta profundamente la manera en que las personas se perciben a sí mismas, y por el otro lado, retoman elementos del postestructuralismo francés. La influencia del movimiento de liberación gay estadounidense y el impacto intelectual de la publicación, en 1976, del primer volumen de La historia de la sexualidad, de Michel Foucault, enmarcan la consolidación de la corriente británica del constructivismo social. Sus más conocidos

\footnotetext{
${ }^{6}$ Los autores clásicos de la teoría del "etiquetamiento" son Edwin Lemert y Howard Becker. Thomas Szaz es tal vez su discípulo más conocido. Véase bibliografía.
} 
representantes son Jeffrey Weeks, cuya provocadora declaración, "Identity is not a destiny but a choice"7 ("La identidad no es un destino sino una decisión" se volvió un slogan del movimiento gay), y Ken Plummer, autor de varios libros sobre homosexualidad y editor del journal académico Sexualities. ${ }^{8}$ Ambos, y muchos más que siguieron sus enseñanzas, utilizaron a Foucault como la base de sus teorizaciones. Aunque Foucault es un ejemplo brillante de la nueva historia cultural, e indudablemente desarrolla conceptos útiles para el estudio de la sexualidad (más en su fase de "arquelogía" que en la de "genealogía") como sus coupures (quiebres), una gran limitación de su pensamiento radica en su ceguera ante la diferencia sexual. ${ }^{9}$ La mayoría de los constructivistas consagraron el segundo capítulo ("La implantación perversa") del primer volumen del trabajo de Foucault como la principal referencia teórica sobre la que "construyeron" un nuevo discurso, liberador y radical, respecto a la sexualidad humana.

Si bien la perspectiva del construccionismo social tuvo el mérito de incorporar el tema de la maleabilidad cultural y del cambio histórico al estudio de la sexualidad humana, rápidamente se convirtió en la perspectiva que adoptaron los intelectuales orgánicos del movimiento lésbico/gay, y su influencia creció hasta convertirse en Estados Unidos en el discurso oficial gay sobre la sexualidad. El constructivismo, como postura "politically correct", 10 volvió al término homosexual en un adjetivo que sólo se debía utilizar para designar ciertos actos o prácticas, y jamás como un sustantivo para designar a cierto tipo de personas, por ejemplo: "ese homosexual a quien quiero tanto".

\footnotetext{
${ }^{7}$ Esta complejidad está lejos de la declaración de Weeks en "Questions of Identity", en The Cultural Construction of Sexuality, editado por Pat Caplan, Tavistock, Londres, 1987, p. 47.

${ }^{8}$ La revista Sexualities, dirigida por Plummer, se ha convertido en una herramienta valiosa de discusión sobre los aspectos culturales de la sexualidad.

${ }^{9}$ Esto lo trata Isaac D. Balbus en "Michel Foucault y el poder del discurso feminista", en Seyla Benhabib y Druucilla Cornell (eds.), 1990, Teoría feminista y teoría crítica, Edicions Alfons El Magnanim, Generalitat Valenciana.

${ }^{10}$ Wayne R. Dynes, "Wrestling with the Social Boa Constructor", en E. Stein, Forms of Desire, op. cit.
}

El acierto indudable de los constructivistas ha sido preguntarse sobre cómo se da el cambio histórico en las pautas de conducta sexual, a partir de pensar que los seres humanos estamos inmersos en un proceso dinámico de evolución cultural y que este hecho debería seguro impactar a las conductas y reglas sexuales. Su error fundamental ha sido su incomprensión de que la conducta sexual tiene también determinaciones psíquicas, cuyo peso es sustantivo.

De los cinco trabajos que aquí se publican, tres se refieren exclusivamente a cuestiones de identidad/orientación homosexual. Me hubiera gustado que Guillermo Núñez, Porfirio Miguel Hernández Cabrera y César Octavio González Pérez se ubicaran más claramente ante esta controversia: ¿qué determina la orientación sexual? Intentar responder a esta interrogante obliga a distinguir entre las prácticas sexuales, la pulsión y el deseo, y tal distinción nos ubica en un complejo panorama, donde las identidades y las valoraciones culturales se mezclan con la represión y el voluntarismo. Tomo un ejemplo elocuente: "No nacimos ni nos hicimos, sólo lo decidimos." Esta es la leyenda de la manta con la que el grupo Unigay participó en la XX Marcha del Orgullo Lésbico, Gay, Bisexual y Transgenérico el 27 de junio de 1998. La frase es un indicador muy significativo de cómo se concibe el ser gay, que condensa la actitud generalizada de hablar, por ejemplo, de "preferencia” sexual. Esta mistificación voluntarista sobre lo que es la orientación sexual abre un flanco muy riesgoso, tanto en términos políticos como personales. No sólo me impactó leer la frase, sino que también me sorprendió que Porfirio Hernández Cabrera no la comente ni cuestione. La concepción implícita - la orientación sexual como una decisión- confunde prácticas con deseo. Claro que podemos "decidir" tener una relación homosexual; "decisiones" de ese tipo surgen por curiosidad, por privación (como en las cárceles y conventos), por desafíos, por mil y otras causas. Pero una cosa es "decidir" con qué tipo de cuerpo tienes relaciones sexuales o eróticas, y otra muy distinta es quién te despierta deseo. También hay muchas personas homosexuales que "deciden" casarse y tener hijos. Pero la cuestión álgida de expresar un deseo distinto al que la cultura valida como "natural" o "normal" remite a la imposibilidad de cambiar a voluntad el deseo. 
Preguntarse por la identidad gay es más que averiguar qué pasa con un número cada vez mayor de personas cuyas experiencias de vida no se ajustan a la heteronormatividad imperante. Si bien comparto totalmente la opinión de González Pérez sobre Bourdieu como un autor fundamental para trabajar el tema de la identidad gay, me hubiera gustado que ampliara su reflexión más allá del concepto de campo social y que incorporara el concepto de habitus, que articula mejor otros elementos de la teoría de Bourdieu. La profunda reflexión que Bourdieu despliega a lo largo de treinta años de trabajos reconstruye lo más cuidadosamente posible cómo los sujetos aprehenden y vuelven subjetivas relaciones sociales e históricas.

El concepto de habitus se refiere a "sistemas perdurables y transponibles de esquemas de percepción, apreciación y acción, resultantes de la institución de lo social en los cuerpos" (Bourdieu, 1995: 87). La cultura, el lenguaje, la crianza, inculcan en las personas ciertas normas y valores profundamente tácitos, que se consideran “naturales". El habitus reproduce estas disposiciones estructuradas de manera no consciente, regulando y armonizando las acciones.

Bourdieu señala que entre los esquemas de "pensamiento impensado" está la heteronormatividad de la vida sexual. Encarar de manera crítica la problemática que Guillermo Núñez señala como "complejos procesos de negociación, acomodamiento, resistencia y subversión de las identidades sexuales" conduce a revisar tanto los efectos consistentes de la simbolización y el condicionamiento en los cuerpos de las personas, como las fugas, resistencias y rupturas que los sujetos llevan a cabo frente a la imposición cultural del género, que inculca la heteronormatividad de la vida sexual.

El deseo humano no tiene más límite que el que la cultura logra imponerle y existen básicamente dos cuerpos

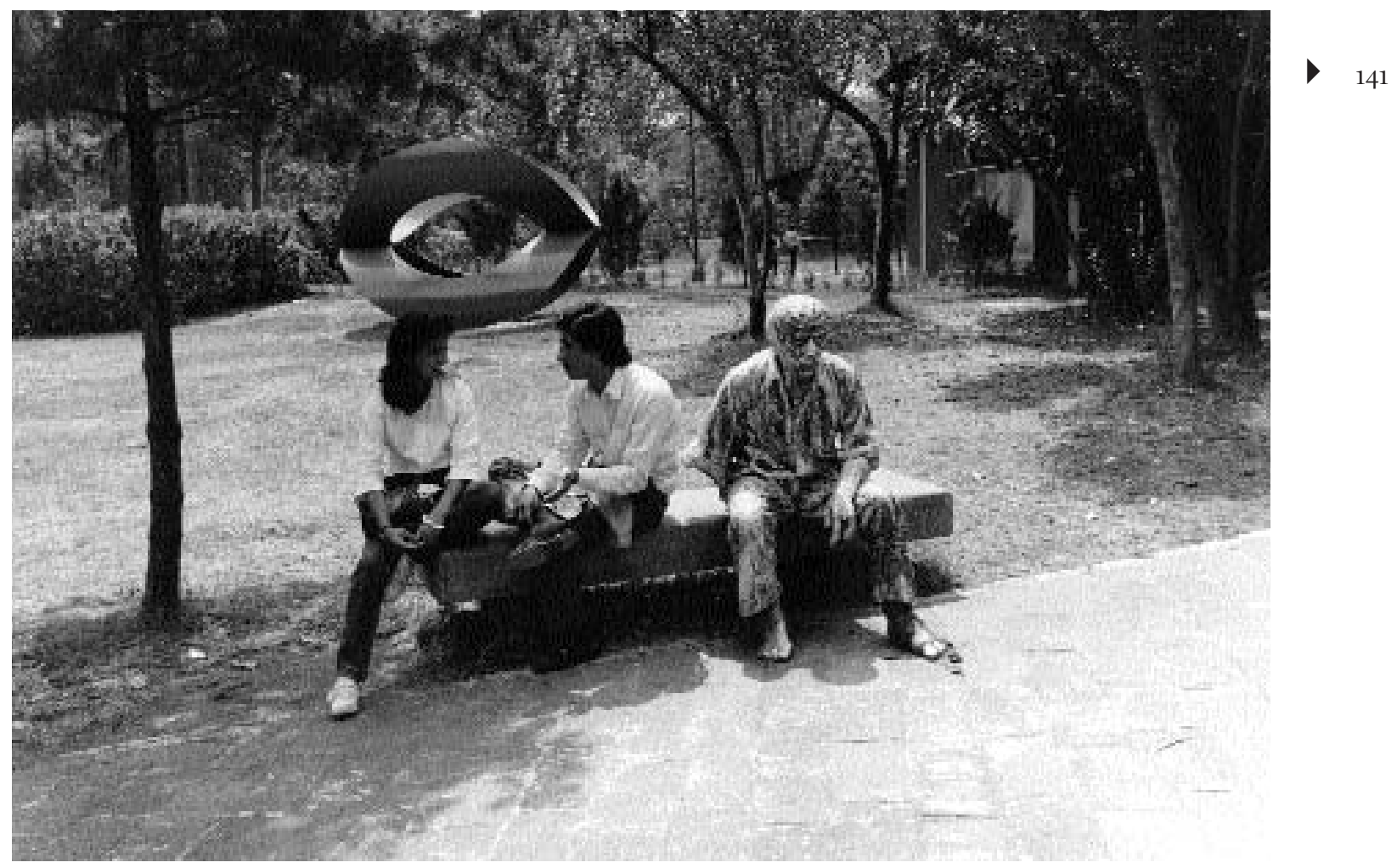

Sin testigos, Jorge Acevedo 


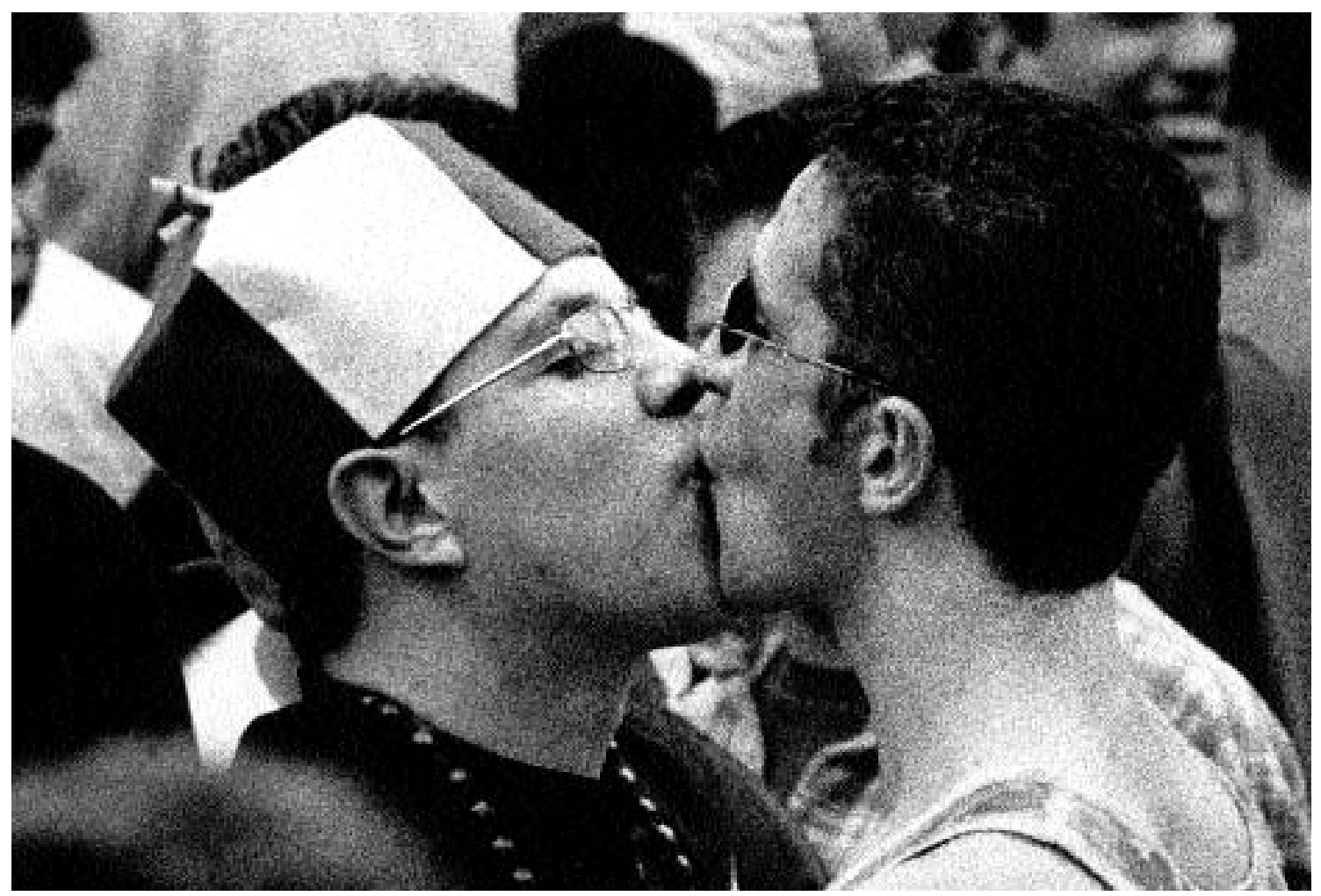

Sin título, Ricardo Ramírez Arriola

en los que encauzar la pasión, por eso hay dos formas de estructuración psíquica - heterosexualidad y homosexualidad- y también por eso existe la práctica de la bisexualidad y las vivencias de los transgéneros y transexuales. Para registrar las formas en que el cuerpo es percibido por un entorno perceptivo estructurado por el género es primordial el concepto clave de habitus, entendido como una "subjetividad socializada", o como el conjunto de relaciones históricas "depositadas" en los cuerpos individuales en forma de esquemas mentales y corporales de percepción, apreciación y acción.

Me hubiera gustado que, por ejemplo, Patricia Ponce lo incorporara a su trabajo, en vez de sólo afirmar que "la sociedad local prefiere el modelo tradicional heterosexual: hombre-mujer", afirmación que no da cuenta de los mecanismos de retransmisión por los cuales las estructuras mentales de las personas toman forma ("se encarnan”) en la actividad de la sociedad. El habitus es sumamente útil para reflexionar sobre la dominación de la ideología heterosexista, de las personas heterosexuales sobre las personas homosexuales, lesbianas, gays, transexuales o queers (o sea, las personas que no asumen los habitus femeninos y masculinos que corresponden a la prescripción de género en materia de sexualidad $y$ afectividad).

También me hubiera gustado que González Pérez reconociera que la violencia simbólica es un mecanismo opresor sumamente eficaz precisamente por la introyección que las personas hacen del género. La definición que consigna González Pérez ${ }^{11}$ deja fuera lo esencial de la

\footnotetext{
11 González Pérez dice: "Bourdieu define la violencia simbólica como toda aquella estrategia que trate de imponer una visión del mundo como la mejor para los 'otros' y que adquiere diferentes matices en nuestra sociedad: la imposición de estigmas, la segregación, la exclusión física y legal."
} 
violencia simbólica, que es la parte de introyeccción y aceptación de las personas violentadas, en el sentido de Gramsci de hegemonía: dominación con consentimiento. Violencia simbólica es un concepto que Bourdieu ha trabajado y retrabajado en varios de sus textos, pues es uno de los hilos conductores de su reflexión. Su ensayo clásico dedicado al concepto ${ }^{12}$ define violencia simbólica como aquella que se ejerce sobre un agente social con su complicidad o consentimiento. Por eso Bourdieu afirma que no se puede comprender la violencia simbólica a menos que se abandone totalmente la oposición escolástica entre coerción y consentimiento, imposición externa e impulso interno.

El punto es cómo las personas dominadas aplican - a la relación de dominación en la que se encuentran atrapadas y a las personas a través de las cuales esta relación se realiza- esquemas no pensados de pensamiento producto de la encarnación de esta relación de poder y que por lo tanto las llevan a construir esta relación desde el punto de vista del dominante como natural. ${ }^{13}$

La complejidad de las teorizaciones de Bourdieu tiene, además, un elemento extra, que también me hubiera gustado encontrar en estos trabajos: la autorreflexión del investigador. De los cinco artículos, cuatro (Núñez, Hernández Cabrera, Rodríguez y Ponce) se nutren de un original trabajo de campo. La etnografía es tanto una forma particular de investigación como el producto escrito de una investigación de campo. A diferencia de mucha de la investigación en ciencias sociales, hecha para probar marcos teóricos o hipótesis, la etnografía es una vía fecunda para registrar la infinita combinación de expresiones individuales que se encuentran en el comportamiento social de las personas y que se reflejan en los arreglos sociales, las relaciones de parentesco, las costumbres sexuales, las concepciones religiosas, las prácticas de la vida cotidiana, etcétera. Los cuatro trabajos de corte etnográfico

\footnotetext{
12 Pierre Bourdieu, 1988, "Social Space and Symbolic Power", en Sociological Theory, 7, núm. 1, junio.

${ }^{13}$ En su reciente obra La dominación masculina, Bourdieu dedica un apéndice a "Algunas cuestiones sobre el movimiento de gays y lesbianas" (p. 143) y destaca precisamente la violencia simbólica como un mecanismo opresor sumamente eficaz contra ese colectivo social.
}

ofrecen materiales inéditos, que ayudan a ir armando el complejo rompecabezas sobre las prácticas y vivencias de la sexualidad entre los mexicanos, pero ninguno de los cuatro tiene una perspectiva autorreflexiva.

La reflexividad implica la autorreflexión de quien investiga sobre las formas en que los productos de la investigación son afectados por el personal que investiga y por los procesos de investigación. El trabajo de campo etnográfico se realiza en un contexto relacional, lo cual requiere sistematizar una serie de vivencias y de intercambios personales intensos. "Leer" las expresiones de los informantes en busca de lo que revelan de la cultura de un grupo es una tarea que está sesgada por el posicionamiento de quien investiga. Antes, con la intención de garantizar una cierta objetividad, quien investigaba trataba de reducir o controlar los efectos que producía: desde intentar mantener a distancia la interacción, "borrar" al investigador (ocultar su identidad y su ideología) y hacerlo pasar desapercibido, hasta cuestiones formales como estructurar las entrevistas al máximo para que la subjetividad de quien las aplicara no afectara. Hoy se elige la reflexividad, lo que requiere asumir un proceso autorreferencial y detectar así los elementos que influyen.

La antropología reflexiva ${ }^{14}$ insiste en lo difícil que resulta deslindar los procesos que involucran a la subjetividad. Los objetivos de investigación se construyen no sólo insertos en tendencias cognitivas que marcan las interpretaciones intelectuales sino también (casi diría fundamentalmente) cruzados por factores subjetivos. Si bien la reflexividad es central para las ciencias sociales, es particularmente importante para la etnografía, donde la relación entre quien investiga y la persona investigada es aún más estrecha. Bourdieu señala que el trabajo requerido por la objetivación científica se acompaña de un trabajo —en el sentido psicoanalítico del términoacerca del sujeto de la objetivación. Bourdieu resume su postura señalando que lo más importante no son los resultados propiamente dichos, sino el proceso conforme al cual éstos son obtenidos. Por eso, para Bourdieu, las

\footnotetext{
${ }^{14} \mathrm{El}$ sentido de la antropología reflexiva lo explican Bourdieu y Wacquant (1996). Para una referencia más etnográfica véase Aull Davies (1999).
} 
teorías requieren no un "debate teórico" sino una "aplicación práctica, capaz de refutarlas o confirmarlas o, mejor aún, de especificar y diferenciar su pretensión de generalidad".

Me hubiera encantado encontrarme con un comentario autorreflexivo de Gabriela Rodríguez respecto a las entrevistas que hizo y cómo se sintió. El "olvido" del peso que tiene la subjetividad del investigador me parece que va de la mano con otro olvido, mayor, que es el del pensamiento freudiano. Sólo Patricia Ponce y Gabriela Rodríguez citan a Freud, pero lo hacen como un reconocimiento que no implica realmente incorporar su perspectiva en sus trabajos. Para los tres autores restantes, que se centran en el tema de la identidad gay, existe un olvido total del pensamiento freudiano.

Este "olvido" me parece significativo, y lo inscribo dentro de la tendencia cultural de desdeñar lo pasado por anticuado y correr tras lo nuevo que Russell Jacoby ${ }^{15}$ analizó como amnesia social. Freud es "demasiado antiguo para estar de moda y demasiado nuevo para ser un clásico" (Jacoby, p. 10), sin embargo, creo que sus conceptos y reflexiones siguen siendo fundamentales para abordar los fenómenos que estos autores tratan.

Me hubiera gustado que las dos autoras aludieran más claramente al proceso de represión social, y que los tres autores registraran el carácter polimorfo y perverso de la libido. Que la libido sea polimorfa y perversa quiere decir que nuestro deseo se desparrama en mil formas y se vierte fuera de los cauces previstos para la reproducción. Me hubiera gustado que Guillermo Núñez retomara el planteamiento freudiano sobre la inestabilidad de la identidad sexual, impuesta en un sujeto que es fundamentalmente bisexual, pues sus entrevistas confirman ampliamente la tesis de Freud sobre la calidad indiferenciada de la pulsión sexual.

Cuando Ponce describe la vida en Boca del Cielo, o cuando Núñez entrevista a sus varones homoeróticos, no puedo menos que recordar las palabras de Freud: "El sentimiento de dicha provocado por la satisfacción de una pulsión silvestre, no domeñada por el yo, es

${ }^{15}$ Russell Jacoby, 1984, La amnesia social, Bosch Casa Editorial, Barcelona. incomparablemente más intenso que el obtenido a raíz de la saciedad de una pulsión enfrenada. Aquí encuentra una explicación económica el carácter incoercible de los impulsos perversos, ${ }^{16}$ y acaso también el atractivo de lo prohibido como tal" (Freud, p. 39). ¿De qué, sino del "carácter incoercible" de su deseo, nos hablan los entrevistados por Guillermo Núñez? ¿Y acaso los habitantes de Boca de Cielo, tan bien retratados por Patricia Ponce, no nos muestran el atractivo de lo prohibido como tal?

Me hubiera gustado que la espléndida etnografía de Ponce tuviera un mejor cierre en lo teórico, que el trabajo de Rodríguez, que tiene el mérito de que intenta ampliar el marco conceptual con que se trabaja en etnografía, hubiera hecho más autorreflexión, que el vuelo de pájaro que hace Hernández Cabrera sobre los antecedentes del movimiento gay en México le hubiera hecho más justicia a los grupos que aparecieron antes de 1978 .

Termino con pocas conclusiones. Creer que la orientación sexual es cuestión de preferencia distorsiona la comprensión del fenómeno sexual humano. Aunque desde una postura antropológica si algo se puede afirmar hoy es que no hay una sexualidad "natural" (en todo caso, lo "natural" sería, justamente, que existe una diversidad de sexualidades) la interrogante a esclarecer es si no hay una única forma de vivir la sexualidad y existen una multiplicidad y pluralidad de expresiones sexuales, entonces por qué nos erotizamos con ciertos cuerpos y con otros no. Más allá de la relación intersubjetiva (entre dos sujetos), ¿por qué cuesta tanto trabajo cambiar a voluntad la "orientación" sexual?

Aquí vale la pena incorporar la evidencia psicoanalítica. Mientras que la antropología explora la naturaleza simbólica de la sexualidad y los efectos que esa valoración tiene sobre cómo los seres humanos organizan sus sistemas jurídicos y normativos, el psicoanálisis se plantea algo central: la articulación del deseo con la cultura. Retomo las palabras de Ricoeur: "el objeto mismo del psicoanálisis no es la pulsión — quiero decir la pulsión

\footnotetext{
${ }^{16}$ Hay que entender el sentido en que Freud utiliza el término perverso. Él define como perversión toda forma de conducta sexual que se desvía de la norma cultural de cópula genital heterosexual, pero insiste en la perversión polimorfa de toda la sexualidad humana.
} 
sola, la pulsión desnuda — sino la relación del ser de deseo con el ser de cultura". ${ }^{17}$

Ése es el quid, creo yo, de la investigación y reflexión antropológica sobre la sexualidad humana: lo que ocurre en la cultura con el deseo, los deseos. Freud dijo que el ser humano se vuelve neurótico porque no puede soportar la medida de frustración que la sociedad le impone en aras de sus ideales culturales. La neurosis moderna generalizada —el malestar en la cultura — tiene que ver con la represión de la sexualidad. Para Freud, satisfacciones como las del artista o el intelectual o científico — “más finas y superiores"— no tienen la intensidad que produce saciar mociones pulsionales más groseras, primarias porque "no conmueven nuestra corporeidad".

Conmover la corporeidad dice Freud, y no se refiere sólo a lo anatómico. El cuerpo es la envoltura del sujeto, y en él se encuentran pulsión y cultura. El cuerpo resulta algo así como una bisagra que articula lo social y lo psíquico. ${ }^{18}$ La comprensión del entramado de esa bisagra psíquico/social permite una nueva lectura de las sexualidades, ya que la sexualidad tiene que ver tanto con la simbolización social como con la imaginarización psíquica. Aceptarnos como seres biopsicosociales lleva a conceptualizar al cuerpo reconociendo su entramado de carne, inconsciente y mente. Este hecho biopsicosocial con toda la carga libidinal que conlleva, entra en conflicto con la cultura.

Freud ${ }^{19}$ expresa que: "Algo que es común a ambos sexos ha sido comprimido, en virtud de la diferencia entre los sexos, en una forma de expresión otra”. ¿Qué quiere decir? Que algo que ambos compartimos es forzado a tomar una forma en un sexo y otra en otro. Freud continúa: "Lo que en ambos casos cae bajo la represión es lo propio del sexo contrario." Si recontextualizamos el

\footnotetext{
${ }^{17}$ Paul Ricoeur, 1974, "Psicoanálisis y cultura", en Varios autores, Sociología contra psicoanálisis, Ediciones Martínez Roca, Barcelona, p. 208. ${ }^{18}$ Claro que cuando se analizan cuestiones que pertenecen a los dos ámbitos - el social y el psíquico- surgen escollos metodológicos sustantivos: hay que distinguir el ámbito de lo psíquico del ámbito de lo social, y tener presente que el psicoanálisis plantea la existencia de una realidad psíquica, distinta a la marca implacable de la socialización. ${ }^{19}$ Sigmund Freud, 1937, "Análisis terminable e interminable", en Obras completas, t. XXIII, Amorrortu Editores, pp. 251-252.
}

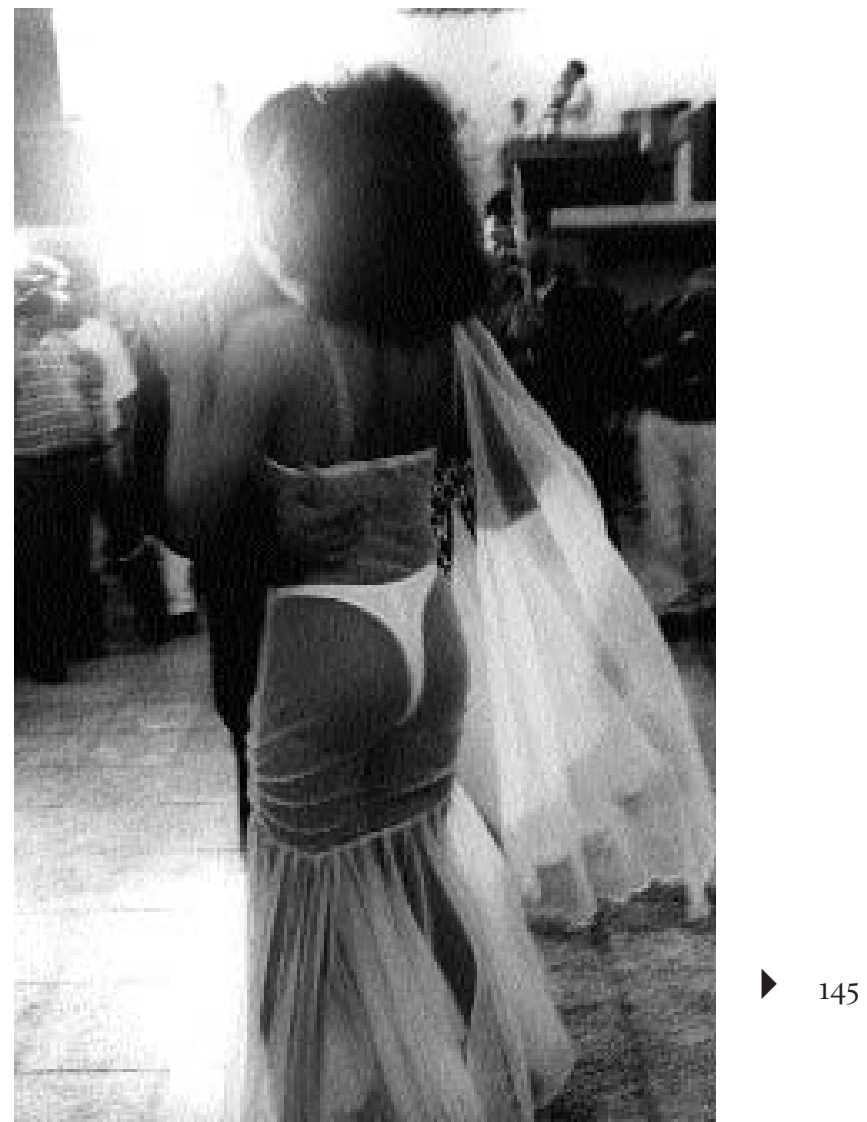

Ángel de la noche, Jorge Acevedo

señalamiento de Freud, como hace Stephen Mitchell, ${ }^{20}$ de la experiencia humana completa sólo conocemos dos deformaciones truncadas. Esto, expresado desde Platón en la nostalgia por esos seres de dos sexos que míticamente fuimos, nos plantea uno de los grandes dilemas de la vida: ¿cuánto de lo que perdemos de la potencialidad que tenemos del sexo opuesto es una pérdida inevitable, consecuencia trágica del autodesarrollo, del proceso de convertirse en sujetos sexuados, y cuánto de la pérdida se debe a una polarización rígida de los papeles sexuales?

\footnotetext{
20 Stephen Mitchell, 1996, “Gender and Sexual Orientation”, en Gen-
} der \&̊ Psychoanalysis, vol. 1, núm. 1, enero. 
Como reconoce María Antonieta Torres Arias: "Hay una pluralidad de respuestas ante lo pulsional que escapa a la simbolización y se sitúa al margen del lenguaje."21 Tal vez nombrarlas y simbolizarlas sea el desafío para darles un cauce legítimo en este nuevo milenio. Por ello la pregunta urgente hoy, que se desprende de este conjunto de trabajos, es: ¿qué ocurre con nuestra bisexualidad innata? Precisamente para ir aceptando nuestra inefable condición de seres poliformos perversos, y así poder darle un estatuto simbólico (cultural) distinto, es necesario hacer la labor que los autores aquí publicados realizan: explorar las múltiples realidades de prácticas e identidades cambiantes. Por eso, estos trabajos encarnan varios de los méritos y problemas que enfrentan quienes se dedican a la antropología para investigar y reflexionar sobre un tema tan fluido como la sexualidad, que se monta sobre la oscura y reprimida pulsión bisexual que todos tenemos.

A pesar de tener una sexuación distinta, el destino infausto que compartimos mujeres y hombres como seres humanos incompletos y escindidos, y la amplia gama de desventuras y goces que vivimos, nos une más que las diferencias que se pretenden establecer con los gastados criterios tradicionales de heterosexual $\mathrm{u}$ homosexual, de masculino o femenino, de hombre o mujer. Si, como el psicoanálisis sostiene, el conflicto del sujeto consigo mismo no puede ser reducido a ningún arreglo social, entonces nos deberíamos proponer una nueva lectura del significado de los conflictos ligados a la sexuación, a la diferencia sexual, al género, a la estructuración del deseo. Estoy segura que quienes se comprometan con las tareas necesarias para una mejor comprensión de los procesos de construcción del sujeto, sin olvidar ni la materialidad de los cuerpos ni la realidad psíquica, se beneficiarán de la lectura de este conjunto de trabajos.

Ciudad de México, 15 de mayo del 2001

${ }^{21}$ María Antonieta Torres Arias, 1994, "La homosexualidad a debate”, en Debate Feminista, núm. 10, México.

\section{Bibliografía citada}

Aull Davies, Charlotte, 1999, Reflexive Anthroplogy. A Guide to Researching Selves and Others, Routledge, Lonres.

D. Balbus, Isaac, 1990, "Michel Foucault y el poder del discurso feminista”, en Seyla Benhabib y Druucilla Cornell (eds.), Teoría feminista y teoría crítica, Edicions Alfons El Magnanim, Generalitat Valenciana.

Becker, Howard, 1973, Outsiders: Studies in the Sociology of Deviance, Free Press, Nueva York.

Bourdieu, Pierre, 1988(a), "Social Space and Symbolic Power", en Sociological Theory, 7, núm. 1, junio.

—_, 1998(b), La dominación masculina, Anagrama, Barcelona.

— y Loic J. D. Wacquant, 1995, Respuestas. Por una antropología reflexiva, Grijalbo, México.

Dynes, Wayne R., "Wrestling with the Social Boa Constructor", en E. Stein, Forms of Desire, cit.

Freud, Sigmund, 1930, "El malestar en la cultura", en Obras completas, t. XXI, Amorrortu Editores, pp. 65-140.

__ 1937, "Análisis terminable e interminable", en Obras completas, t. XXIII, Amorrortu Editores, pp. 251-252.

Jacoby, Russell, 1984, La amnesia social, Bosch Casa Editorial, Barcelona.

Lemert, Edwin, 1951, Human Deviance, Social Problems and Social Control, McGraw-Hill, Nueva York.

Mitchell, Stephen, 1996, "Gender and Sexual Orientation", en Gender and Psychoanalysis, vol. 1, núm. 1, enero.

Ricoeur, Paul, 1974, "Psicoanálisis y cultura", en Varios autores, Sociología contra psicoanálisis, Ediciones Martínez Roca, Barcelona, p. 208.

Sexualities. Studies in Culture and Society, Journal publicado por Sage Publications desde 1998, director Ken Plummer.

Stein, Edward, 1992, "The Essentials of Constructionism and the Construction of Essentialism", en E. Stein, Forms of Desire. Sexual Orientation and the Social Constructionist Controversy, Routledge, Londres.

Sterling, Anne Fausto, 1993, "The Five Sexes. Why Male and Female are Not Enough", en The Sciences, marzo/abril.

Szaz, Thomas, 1975, El mito de la enfermedad mental, Amorrortu Editores, Buenos Aires.

Vance, Carol, 1991, "Anthropology Rediscovers Sexuality: a Theoretical Comment", en Social Science and Medicine, 33, núm. 8 .

Weeks, Jeffrey, 1987, "Questions of identity", en Pat Caplan (ed.), The Cultural Construction of Sexuality, Tavistock, Londres, p. 47. 